\title{
Análise dos Artigos Publicados na Revista Turismo em Análise entre os Anos de 2004 e 2015
}

Camila Lopes Seixas ${ }^{a}$ Monica Filomena Caron ${ }^{b}$

\section{Resumo}

Na pesquisa foram analisadas as publicações da revista Turismo em Análise entre os anos de 2004 e 2015, identificando-se a formação acadêmica dos autores, as disciplinas, áreas ou abordagens de estudos envolvidas nas pesquisas, além da forma como estas têm sido construtivas para o desenvolvimento das pesquisas e de sua episteme. Na análise operou-se também um mapeamento das metodologias, um estudo bibliográfico do tema metodologia e da metodologia específica para o turismo e uma busca documental no site da revista e em revistas impressas, coletadas na Escola de Comunicação e Artes da Universidade de São Paulo (ECA-USP). Foi feito um mapeamento dos artigos identificando-se o campo de atividade humana; a utilização dos resultados; a natureza e procedência dos dados; o grau de generalização dos resultados e as técnicas e os instrumentos de observação. Os resultados, demonstrados em tabelas e gráficos, indicaram um aumento de pesquisadores das áreas de administração, geografia, economia e comunicação publicando sobre turismo, e um aumento bastante significativo nos últimos doze anos de pesquisadores doutores das áreas do turismo. Em relação às abordagens de estudos, identificou-se uma tendência de aumento no planejamento e nos negócios empresariais (administração).

Palavras-chave: Metodologia; Pesquisa em turismo; Turismo em Análise.

\section{Abstract \\ Analysis of the articles published in the journal Turismo em Análise between 2004 and 2015}

This research analyzed publications of the journal Turismo em Análise in the period between 2004 and 2015. The authors' academic training was scrutinized, as well as university subjects, fields, or study approaches embraced by Tourism studies, including how relevant they were in the development of research and its episteme. Such analysis consisted of mapping of methodologies, a bibliographic study on methodology and on Tourism methodology, documentary research on the journal's website and in printed copies provided by the School of Arts and Communication (ECA - Escola de Comunicação e Artes) from the University of São Paulo (USP - Universidade de São Paulo). Articles were mapped to identify their: field of human activity; usage of the results; data nature and source; levels of generalization of results; observation techniques and instruments. Our results are presented in tables and charts, which indicate an

1. 0 trabalho foi realizado em pesquisa de iniciação científica, com bolsa do CNPQ-PIBIC, e finalizado como trabalho de conclusão de curso de Bacharelado em Turismo.

a. Mestranda em Sustentabilidade na Gestão Ambiental da Universidade Federal de São Carlos (UFSC). Sorocaba, São Paulo, Brasil. E-mail: camilaseixas@hotmail.com

b. Pós-doutora em Linguística pela Universidade Estadual de Campinas (Unicamp). Campinas, São Paulo, Brasil. Docente do Departamento de Geografia, Turismo e Humanidades da Universidade Federal de São Carlos. Sorocaba, São Paulo, Brasil. E-mail: monica.caron@gmail.com 
increasing number of publications concerning Tourism by researchers from the fields of Administration, Geography, Economics, and Communication, as well as a significant increment of PhD researchers in the fields of Tourism in the period analyzed. Regarding study approaches, a tendency to the emergence of planning and business (administration) studies was observed.

Keywords: Methodology; Tourism research; Tourism under analysis; Turismo em Análise.

\section{Resumen}

Análisis de los artículos de la revista Turismo em Análise publicados entre los años 2004 y 2015

En la investigación se analizaron publicaciones de la revista Turismo em Análise entre los años 2004 y 2015, identificándose la formación académica de los autores, las disciplinas, áreas o enfoques de estudios involucrados en las investigaciones de Turismo, además de la forma en que han sido constructivas para el desarrollo de la investigación y su episteme. En el análisis se operó también un levantamiento de las metodologías, un estudio bibliográfico del tema metodología y de la metodología específica para el turismo, y una búsqueda documental en el sitio web de la revista y en revistas impresas, recogidas en la Escuela de Comunicación y Artes de la Universidad de São Paulo - ECA USP (Escola de Comunicação e Artes da Universidade de São Paulo). Se hizo un levantamiento de los artículos identificándose el campo de actividad humana; la utilización de los resultados; la naturaleza y procedencia de los datos; el grado de generalización de los resultados y; las técnicas y los instrumentos de observación. Los resultados se tabularon y se presentaron en las tablas y gráficos, indicando un aumento de investigadores de las áreas de Administración, Geografía, Economía y Comunicación, publicando sobre turismo, y un aumento muy significativo en los últimos doce años de investigadores de doctorado en las áreas de Turismo. En relación a los enfoques de estudios, se identificó una tendencia de aumento en la planificación y en la actividad empresarial (administración).

Palabras clave: Metodología; Investigación en Turismo; Turismo em Análise.

\section{INTRODUÇÃO}

A fim de discutir a importância da metodologia e do avanço nas pesquisas em turismo, este trabalho buscou abordar as bibliografias de estudos já realizados acerca de metodologias dos estudos do turismo na revista Turismo em Análise. A hipótese era de que tal abordagem possibilitaria levantar dados significativos, apontamentos e observações sobre quem está publicando, o que está sendo publicado e como se tem pesquisado e os avanços e os processos de amadurecimento na qualidade das pesquisas. Para tal investigação, delimitou-se o período compreendido entre os anos 2004 e 2015. Inicialmente, o período analisado fora de 2004 a 2013, em estudo realizado durante os anos de 2013 e 2014, em pesquisa de iniciação científica. Durante os anos de 2015 e 2016 a análise foi atualizada para a realização do trabalho de conclusão de curso. 0 objetivo inicial foi abranger dez anos de publicações da revista, mas com efeito acrescentaram-se dois anos, a fim de obter-se uma amostragem mais significativa e atualizada dos dados.

Todos os artigos foram lidos na íntegra com o objetivo de identificar e mapear metodologias utilizadas, temas de estudos, disciplinas envolvidas, abordagens e enfoques de estudos e formações acadêmicas dos pesquisadores. Sobre estes, quando não havia indicação, realizou-se uma busca no currículo lattes. Nos tópicos de discussões teóricas dos artigos foi feita uma leitura mais dinâmica, com o 
intuito de investigar palavras-chave que pudessem fornecer informações para a análise das disciplinas envolvidas e abordagens de estudos.

Com efeito, entende-se que a importância da metodologia dá-se, principalmente, pelo resultado que esta acarreta na pesquisa; é a pedra angular, pois, se não for eficaz, o resultado obviamente não será eficiente, reconhecido e/ou útil para a geração de novas pesquisas, ou poderá atrapalhar outras pesquisas e contribuir para o regresso nos processos científicos. No turismo estas questões são ainda mais relevantes, por tratar-se de uma área de estudos na qual ainda não há um tesauro definido, o que faz com que, consequentemente, não haja metodologias definidas. Novas propostas têm sido elaboradas e amadurecidas em relação a teorias, conceitos, definições e metodologias, além de consultadas as obras e os autores clássicos do turismo, renomados e reconhecidos pela academia nacional e internacional. Nota-se, com o trabalho de pesquisa aqui apresentado, que existe diálogo entre os autores e que houve avanços significativos na área.

No artigo inicialmente apresenta-se a metodologia utilizada na pesquisa. Em seguida, é feita uma discussão sobre a importância da metodologia científica, apresentando-se obras relevantes e estudos históricos sobre as metodologias científicas. Os resultados e as discussões são apresentadas por meio de gráficos e de discussão sobre a formação acadêmica dos pesquisadores, por abordagens de estudos dos artigos publicados e por mapeamento metodológico, incluindo uma tabela com todas as metodologias encontradas nos artigos. Por fim, encontram-se as considerações finais.

\section{METODOLOGIA}

Utilizaram-se bibliografias de estudos metodológicos em geral e estudos metodológicos e episteme do turismo. Foram analisadas 33 edições da revista Turismo em Análise, contemplando 12 anos de publicação e cerca de 301 artigos, compreendendo o período entre 2004 e 2015, no qual a revista teve periodicidade semestral até o ano de 2007 (publicação nos meses de maio e novembro) e periodicidade trimestral a partir de 2008 (publicação nos meses de abril, agosto e dezembro).

Inicialmente identificaram-se as formações acadêmicas dos pesquisadores (graduação, mestrado, doutorado e pós-doutorado). Depois, analisou-se o tema de estudos, observando se a pesquisa fazia parte dos segmentos turísticos e quais eram estes segmentos. Em seguida, identificou-se quais eram as disciplinas envolvidas e as abordagens de estudos, os temas e enfoques das pesquisas e o que estava sendo abordado. Por último, realizou-se um mapeamento das metodologias utilizadas nas pesquisas, indicando se foram de caráter mono, inter e/ou multidisciplinar; se era uma pesquisa pura/básica ou fundamental aplicada; a natureza dos dados (objetivos ou subjetivos); a procedência dos dados (primários, estudo de caso, ou secundários, com análises econômicas, revisões); o grau de generalização dos resultados (censitária, amostragem intencional, amostragem aleatória, amostragem por conveniência); as técnicas e instrumentos de observação (direta, não participante, indireta, participante, consulta bibliográfica, questionários, entrevistas, anamnese, biografia, consulta de dados); o nível de interpretação (identificativas, descritivas, mensurativas, explicativas e exploratórias); e, por fim, as metodologias construídas/desenvolvidas para uma pesquisa 
específica ou as metodologias já existentes, mais utilizadas por outras áreas de estudos/ciências ou já muito utilizadas no turismo e, a partir de tal mapeamento de dados, traçou-se a tendência e discutiu-se sobre os pontos observados, analisando-se a evolução da pesquisa em turismo nos últimos doze anos.

As metodologias e todos os itens de análise foram mapeados por meio do software Excel, gerando 13 gráficos e 12 tabelas, sintetizados neste artigo em 4 gráficos e 1 tabela, e os principais resultados foram apresentados em números e discussões. 0 mapeamento foi orientado pelo livro Turismo e pesquisa científicapensamento internacional x situação brasileira, de Rejowski (2010), com algumas alterações. Segue abaixo o roteiro de análise dos artigos:

- Campo de atividade humana: monodisciplinar, interdisciplinar e multidisciplinar;

- Utilização dos resultados: pesquisa pura/básica, ou fundamental e aplicada;

- Natureza dos dados: objetiva ou subjetiva;

- Procedência dos dados: primários (estudos de casos) ou secundários (análises econômicas, revisões);

- Grau de generalização dos resultados: censitária, amostragem intencional, amostragem aleatória, amostragem por conveniência;

- Técnicas e instrumentos de observação: direta, não participante, participante, indireta, consulta bibliográfica, questionários, entrevistas, anamnese, biografia e consulta de dados;

- Nível de interpretação: identificativas, descritivas, mensurativas, explicativas e exploratória.

Por fim, foram tabuladas todas as metodologias específicas, nomeadas nas pesquisas.

\section{Importância da metodologia científica}

É por meio de questionamentos que conseguimos comprovar hipóteses e ideias e/ou levantar novos questionamentos, encontrar informações importantes etc. A ciência pode solucionar problemas de ordem política e econômica, alavancando desenvolvimentos e transformando realidades estancadas seja por falta de agentes interlocutores locais seja por uma economia muito explorada de um determinado recurso natural que, ao se esgotar, ocasiona evasão populacional na região/local.

0 turismo, enquanto atividade econômica, passou por longos períodos sendo mal planejado, por falta de bibliografia e de profissionais qualificados. Hoje, ainda que existam muitos profissionais na área, não há valorização e reconhecimento destes em diversos lugares. Tal desvalorização é reforçada principalmente na academia, ou seja, no amadurecimento do turismo enquanto ciência, pela 
quantidade de pesquisadores de formações diversas escrevendo sobre o turismo, uma área de estudo inter e multidisciplinar, que deve ser estudada de dentro para fora, para conhecer sua estrutura, seus conceitos, sua história.

Com o aumento de bibliografias, as formações técnicas e acadêmicas vêm tomando corpo e força e, economicamente, vêm surgindo dados numéricos rentáveis para regiões e países. 0 turismo vem conquistando espaço e atenção acadêmica, pública e política, porém ainda existem fragilidades nas questões acadêmicas que influenciam as outras esferas (pública e política). Todas as áreas hoje reconhecidas como ciências tiveram suas fases de discussões, mudanças, descrenças e universalização do método científico, pois:

a descoberta do método científico no século XVII aumentou no homem a confiança na possibilidade de a ciência conhecer os segredos na natureza. Essa confiança baseia-se na profunda crença na ordem e racionalidade do mundo. 0 método se aperfeiçoa, se universaliza e serve de modelo e inspiração a todas as outras ciências particulares que vão se destacando do corpo da "filosofia natural". É interessante notar que a ligação inicial entre filosofia e ciência por muito tempo persistiu na nomenclatura dos cientistas. Não raro se encontravam livros com o título de "Filosofia natural" para se referir à física. Até hoje temos reminiscências na classificação das "Faculdades de Filosofia", onde podemos estudar não só a própria filosofia, mas também encontramos cursos de matemática, física, química etc. (Aranha \& Martins, 1986, p. 148)

O turismo já passou por inúmeras discussões, discordâncias, conceitos, definições e teorias e está há bastante tempo passando por um processo de universalização e definição dos termos. Barretto (1995) diz que:

durante muitos anos afirmou-se que o turismo estava assentado no tripé de agências, hotéis e transportadoras. Este conceito também precisa ser revisto. No que diz respeito aos hotéis, nem todos são turísticos e nem todo turismo inclui hotel. Há hotéis que atendem principalmente homens de negócios, executivos, portanto não têm sua sobrevivência atrelada ao turismo. 0 turismo inclui alojamento, mas não depende exclusivamente da hotelaria, já que existem vários tipos de alojamentos extra-hoteleiros. (Barretto, 1995, p. 13-14)

Barretto (1995) discute todas as definições de turismo encontradas, desde a primeira, em 1911, proposta por um economista austríaco. Destacam-se nessa discussão as definições e conceitos simplórios, uma vez que não se compreendia a complexidade do turismo como um fenômeno, devido ao fato de não haver escolas destinadas aos estudos turísticos, mas somente especulações e hipóteses sem embasamento e fundamento científico rigoroso.

Em relação à cientificidade, Eco (1976) pondera que um estudo é científico quando possui um objeto de estudo, sendo ele tangível ou intangível, mas reconhecível pelos outros. Após definir o objeto, é preciso que a pesquisa seja inédita ou analisada sob outra ótica, diferente da que foi pensada anteriormente. Além disso, deve também conter uma significância, ou seja, uma contribuição à academia e à sociedade. Por último, deve "fornecer elementos para a verificação e a contestação das hipóteses apresentadas e, portanto, ter uma continuidade pública" (Eco, 1976, p. 23). Esse ponto é de suma importância para a credibilidadede uma ciência, pois é 
uma forma de outros pesquisadores darem continuidade e/ou abrangência à pesquisa. No entanto, para tal, deve haver detalhamento do modo como se chegou a determinado resultado. Eco (1976) considera que, na produção científica, em todas as carreiras, há necessidade de desempenho dos estudantes e envolvimento exclusivo de tutores e/ou professores para a produção das teses. Nesse caso, notou-se na presente pesquisa um aumento de graduandos, por exemplo, publicando com seus professores doutores ou pós-doutores. Além disso,

se o trabalho for bem feito, o fenômeno normal, após a tese, é a irrupção de um grande frenesi de trabalho. Quer-se aprofundar todos os pontos que ficaram em suspenso, ir no encalço das ideias que nos vieram à mente, mas que se teve de suprimir, ler outros livros, escrever ensaios. E isto é sinal de que a tese ativou o seu metabolismo intelectual, que foi uma experiência positiva. É sinal, também, de que já se é vítima de uma coação no sentido de pesquisar, à maneira Chaplin em Tempos Modernos, que continuava a apertar parafusos mesmo depois do trabalho: e será preciso um esforço para se refrear. (Eco, 1976, p. 174)

Esta também pode ser considerada uma maneira de incentivar a pesquisa, por isso, mais uma vez afirma-se que pesquisas são sempre contínuas e há sempre algo novo sendo descoberto ou que instiga o pesquisador a indagar - o grande frenesi para avançar nos seus processos de pesquisas e a busca incessante pelo conhecimento. Dado então que

o aprofundamento da vida científica passa a exigir do estudante uma postura de auto-atividade didática que será, sem dúvida, crítica e rigorosa. Todo o conjunto de recursos que está na base de ensino superior não pode ir além de sua função de fornecer instrumentos para uma atividade criadora. (Severino, 2002, p. 23-24)

As descobertas feitas por meio de pesquisas científicas instigam pesquisadores - não generalizando - a obter maiores conhecimentos das áreas estudadas e incentivam a atividade criadora, o que no caso do turismo vem sendo notado massivamente pela quantidade de metodologias de pesquisas desenvolvidas, muito bem embasadas. Nota-se que a relação da amplitude de metodologias encontradas dá-se, ainda, pelo fato de haver pesquisas sendo realizadas por pesquisadores inter e multidisciplinares, o que considera-se positivo, por haver conhecimentos diversos envolvidos em uma só área. Segundo Koche (2009), "não existe uma única concepção de ciência. Podemos dividi-la em períodos históricos, cada um com modelos e paradigmas teóricos diferentes a respeito da concepção de mundo, de ciência e de método". No entanto, sabe-se que a ciência contemporânea surgiu no início deste século, logo ainda estão em curso muitos paradigmas e discussões epistemológicas, e o turismo participa desse processo de cientificidade da contemporaneidade.

\section{RESULTADOS E DISCUSSÃo}

Os tópicos selecionados para o mapeamento dos textos foram: disciplinas envolvidas nos artigos, formações acadêmicas dos pesquisadores, aporte 
metodológico, campo de atividade humana, utilização dos resultados, natureza e procedência dos dados, grau de generalização dos resultados, técnicas e instrumentos de observação, nível de interpretação e metodologias específicas.

Houve dificuldade para definir as disciplinas envolvidas nas publicações de turismólogos, uma vez que o turismo forma-se a partir da inter e multidisciplinaridade, e em sua produção de conhecimento há um grande entrelace de ciências, configurando-se em um conjunto de áreas. Por exemplo, o turismólogo, ao desenvolver uma pesquisa, aborda simultaneamente conceitos sociológicos, ambientais, econômicos, culturais e técnico-mercadológicos. Em contrapartida, pesquisadores, principalmente das ciências exatas, ignoram, por exemplo, os efeitos sociológicos benéficos ou maléficos provindos da atividade turística. Pesquisadores das ciências humanas (não turismólogos ou sem formação relacionada ao turismo) ignoram efeitos da atividade turística a longo prazo ou minimamente transformadores da condição econômica e qualidade de vida da população autóctone. Pesquisadores com formações nas ciências ambientais/biológicas seguem a linha de abordagem crítica dos pesquisadores das ciências humanas, também desconsiderando os efeitos socioeconômicos transformadores da atividade turística. Poucos propõem métodos de recuperação e/ou minimização dos efeitos destrutivos ou mesmo de maximização dos efeitos educativos, que podem ser operacionalizados pela atividade turística. Comumente, isso é o que ocorre. Pode-se considerar que, de modo geral, apenas aqueles que possuem um estudo minimamente aprofundado e uma leitura neutra em relação à atividade turística podem executar uma análise interdisciplinar do turismo.

Segundo Nechar (2011), os estudos turísticos têm tomado dois rumos, o administrativo, econômico-empresarial, e o da sociologia, teórico-academicista, classificação proposta por Hunzinker e Krapf. Nechar (2011) faz ainda uma análise do pensamento mercadológico, empresarial e sociológico que envolve a produção científica do turismo, dissertando que

a partir de los noventa, se gesta toda una "conciencia de lo ambiental" y del cambio climático de la cual la comunidad académica destacará una corriente orientada hacia la sustentabilidad en las vertientes económica, social y precisamente ambiental. Particularmente el énfasis se pone en la gestión competitiva y sustentable de los destinos turísticos con la finalidad de aumentar el gasto turístico, atraer más visitantes para tener experiencias significativas, mejorar la calidad de vida de los habitantes y conservar el capital ambiental para las generaciones futuras. (Ritchie \& Geoffrey, 2003 apud Nechar, 2011, p. 518)

Essa pesquisa epistemológica demonstra uma preocupação com a não consolidação das áreas do conhecimento do turismo. Temos aqui, mais uma vez, a afirmação da correlação entre mercado turístico e teoria/academia, ou seja, atenta para o quanto os estudos e as pesquisas influem na dinâmica da atividade turística, participando do desenvolvimento econômico, sociológico e empresarial. A atividade turística é interligada a esse conhecimento, fato que será demonstrado nos gráficos a seguir. Há pesquisadores que, para analisar elementos/equipamentos do turismo, utilizam-se de metodologias específicas de sua área de formação, desconsiderando estudos desenvolvidos no turismo ou análises comparativas, analisando, por exemplo, um hotel como uma empresa que trabalha 
com produtivismo da indústria. 0 alerta é que o turismo está inserido no terceiro setor - de serviços - transformando a dinâmica organizacional do empreendimento, de modo que não se deve ignorar os estudos da área de hospitalidade, a qual está totalmente interligada com o turismo.

A pesquisa de Miranda e Rejowski (2012), intitulada "Panorama dos periódicos científicos de turismo e hospitalidade no Brasil", faz uma análise abrangente de publicações em redes eletrônicas de pesquisa em turismo no Brasil, discutindo procedimentos metodológicos. Por sua vez, a pesquisa "Periódicos científicos em turismo: panorama evolutivo e caracterização da revista Turismo em Análise", de Minozzo e Rejowski (2004), faz comparações com outras revistas de pesquisas científicas em turismo, trazendo uma importante afirmação a respeito da Turismo em Análise ao considerar que

a revista cresceu e se consolidou. A tiragem inicial de 300 exemplares cresceu para 500, depois para 700 e hoje perfaz um total de 1000 exemplares. Em 2003 a ECA firmou um convênio com a Editora Aleph, ficando a primeira com a responsabilidade científica e organização do conteúdo, e a segunda com a produção gráfica, distribuição e comercialização. A revista Turismo em Análise possui cerca de 15 anos de existência, nos quais aprimorou-se consideravelmente. Atualmente, nenhuma outra revista periódica nacional possui um acervo de artigos que represente melhor a produção científica de Turismo no período 1990 a 2002. (Minozzo \& Rejowski, 2004, p. 10)

De fato, corrobora essa afirmação a presente pesquisa, pois, além do aumento para três revistas anuais a partir de 2008, observa-se aumento na quantidade de páginas e artigos, na qualidade e complexidade das pesquisas e na quantidade de turismólogos, mestres, doutores e pós-doutores em turismo publicando, dados demonstrados no Gráfico 1.

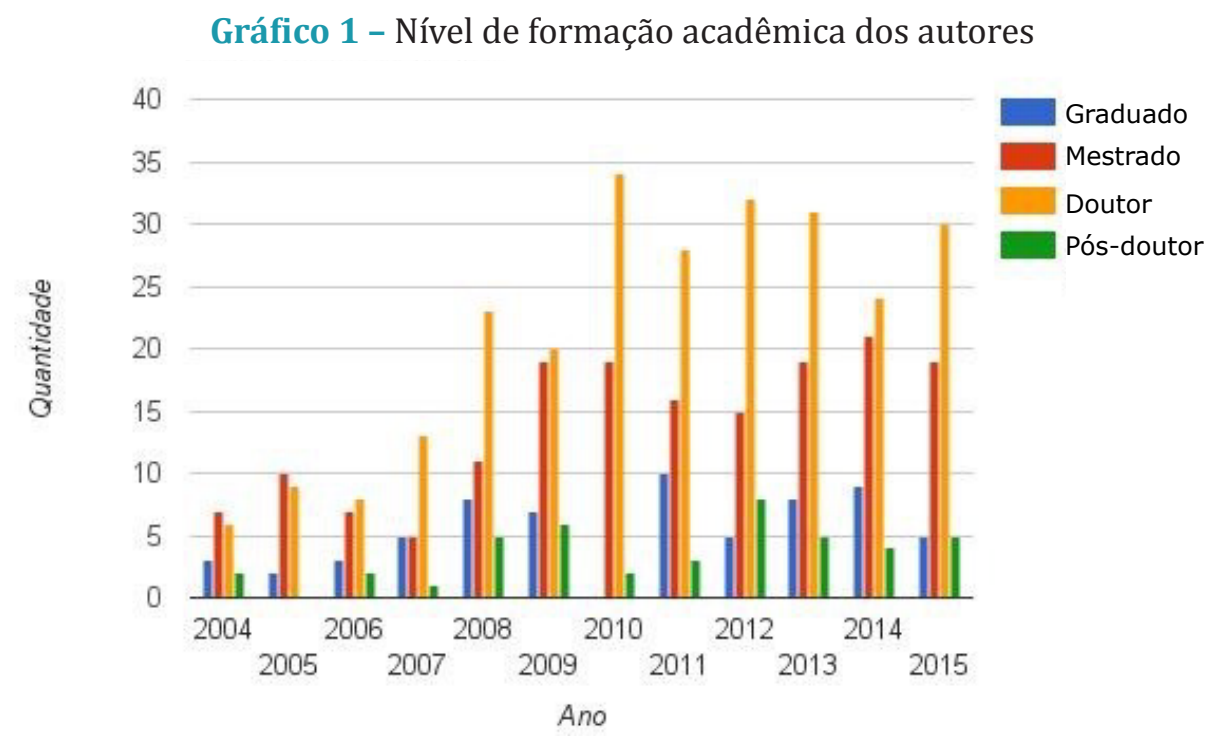

Fonte - Elaborado pelas autoras com dados da pesquisa.

Numa rápida observação, constatou-se que se repetiam frequentemente os autores que publicaram na Turismo em Análise, ou seja, parecia que não havia novos pesquisadores iniciando estudos em turismo. No entanto, o oposto disso 
foi observado numa análise mais acurada. A recorrência de pesquisadores publicando significa que há continuidade, seriedade e avanço nas pesquisas em turismo, pois observou-se que a maioria dos que publicam uma única vez não são das áreas do turismo. A valorização e o reconhecimento dos pesquisadores das áreas do turismo que têm publicado recorrentemente na Turismo em Análise devem ser apontados e reconhecidos como positivos para o avanço da área, pois o acúmulo de conhecimento é importante para o amadurecimento e a qualidade das pesquisas, dado também observado na análise de 12 anos de publicações. Há publicações nas quais não houve aprofundamento mínimo e/ou que foram realizadas por profissionais de outras áreas que não do turismo, mas que não devem ser descartadas em sua totalidade, mas sim utilizadas com cautela, considerando a carência de alguns conhecimentos específicos e, por outro lado, aproveitando os conhecimentos específicos dos campos de estudos de quem publicou. Devem também ser observadas e utilizadas como pontos de partida para análises de outras pesquisas, principalmente as do mesmo caráter, para, assim, talvez de fato comprovar onde houve falhas e acertos, contribuindo para o amadurecimento e avanço da qualidade das pesquisas do campo de estudos do turismo.

O elevado produtivismo científico no campo de conhecimento do turismo foi observado em uma pesquisa de Panosso Netto e Calciolari, publicada em 2010 na Turismo em Análise:

as publicações em turismo aumentaram em número no Brasil durante a década de 1990 e mais especificamente nos anos de 2001, 2002 e 2003 devido ao público consumidor que estava crescendo, ou seja, alunos e professores universitários de turismo. Não foi um crescimento motivado pela importância que o turismo tem no contexto contemporâneo, mas muito mais pela visão dos editores que viram um meio de preencherem uma lacuna do mercado editorial que existia. (Panosso Netto \& Calciolari, 2010, p. 683)

Este aumento de publicações, visto da perspectiva do "preenchimento de uma lacuna", é fato observado também na presente pesquisa, cujos dados corroboram o aumento de publicações por turismólogos e pós-graduados do turismo, também decorrente da criação e do aumento de cursos na área. Contudo, a multidisciplinaridade está cada vez mais presente - é um produtivismo acadêmico bastante nítido e em crescimento.

\section{Formação acadêmica dos autores}

Foram encontrados 466 pesquisadores com 67 diferentes graduações, a maior parte destes com graduação em turismo (157), administração (94) e comunicação (16). Os demais variam entre as diversas áreas das engenharias (44) e outros (155). Em relação à quantidade de mestres, um total de 474 pesquisadores e 22 mestrandos. 0 total de mestres soma 99, sendo a maior parte em administração (117), turismo (63), manejo ambiental (42), economia (29), ciências da comunicação (28), engenharias (27) e geografia (24) e outros (144). A quantidade de doutores soma 278 de 78 doutorados diferentes e 57 doutorandos. Os doutores mais presentes são em: administração (58), sendo que 6 são de 
administração em turismo, comunicação (36), engenharias (24), economia (18), geografia (16), sendo que 1 era de geografia e turismo, economia (19), sendo que 1 era de economia do turismo e meio ambiente, e os demais nas áreas do turismo, entre elas: turismo, desenvolvimento sustentável e ordem territorial (3), gestão em turismo (1), recreação e turismo (1), turismo (3), turismo e desenvolvimento sustentável(1), turismo ehotelaria(1), turismo sustentável(1) eoutros (96). Por fim, os pós-doutores que têm publicado nos últimos 12 anos totalizam 43 de diferentes programas e 2 pós-doutorandos. Os pós-doutores foram em: administração (5), economia (5) e turismo (5). Porém, somam-se 10 para além dos pós-doutores apenas em turismo, mas que contêm outros nomes em composição, que são: gestão em turismo (4), programa de perspectivas científicas de negócios e turismo (1), marketing, qualidade, sustentabilidade, planejamento e gestão de destinos turísticos e hotéis (1), gerenciamento de empresas do setor turístico (1), empreendedorismo do turismo (2), economia do turismo (1) e outros (18). Fora isso, constatou-se 7 pesquisadores sem formação declarada e 33 estrangeiros que não informaram a formação e não possuem currículo lattes. Também foram encontrados cerca de 60 autores que mencionaram suas especializações, MBAs e pós-graduações e 2 tecnólogos em gestão em turismo.

Há colaborações e trocas de experiências entre os investigadores do turismo de diversas formações. Há de se valorizar as metodologias e procedimentos, principalmente neste momento em que o turismo encontra-se em estágio de evolução e avanço científico. Deve-se entender que o método científico

consiste em uma série de procedimentos realizados pelo pesquisador com a finalidade de reduzir as chances de erro. É importante assinalar que o conhecimento científico obtido mediante o emprego do método científico, se expressa em probabilidades. 0 pesquisador trabalha com suposições prováveis e não com verdades absolutas. Assim, a ciência é um conjunto provisório de conhecimentos prováveis que podem ser submetidos a testes e refutados. (Dencker, 1998, p. 17-18)

A partir desse conceito de método científico de Dencker se entende que o método científico estabelece o que fazer e a técnica científica estabelece como fazer. Com isso, compreende-se que a metodologia científica é um diálogo que se estabelece entre método e técnica, que se entrelaçam nas pesquisas. Sem método e técnica, não há ciência. "Três elementos formam a base da investigação científica como ciência: a teoria, o método e a técnica" (Dencker, 1998, p. 23), por isso, a importância da construção da metodologia científica para o turismo, que por ser uma área recente de estudos perde muitas vezes pela ausência de uma metodologia ou de um conjunto de metodologias que estabeleçam credibilidade e solidez às pesquisas. Para tanto,

o que determina o caráter científico do conhecimento é o método utilizado para sua construção. $O$ método especifica o procedimento a ser seguido na busca do conhecimento. Na medida em que o método normaliza os procedimentos científicos, ele não é um instrumento de descoberta. 0 emprego do método, entretanto, é necessário para reduzir a interferência do pesquisador nos resultados. (Dencker, 1998, p. 21) 
Para o turismo, um dos objetivos do conhecimento científico dá-se, pois

o conhecimento é fundamental para a elaboração de planos e projetos de pesquisa em todas as áreas de atuação, sendo a metodologia científica uma importante ferramenta tanto na orientação de microescala, no âmbito empresarial, quanto em macroescala, no caso do planejamento. (Dencker, 1998, p. 24)

Esta afirmação foi corroborada na presente pesquisa e pode ser ilustrada pela análise das tabelas e dos gráficos, que demonstram o significativo crescimento na quantidade de pesquisas voltadas aos negócios empresariais (administração) e ao planejamento do turismo. A seguir são apresentados os Gráficos 2, 3 e 4, com as tendências das áreas de estudos, de graduação, mestrado, doutorado e pós-doutorado, que obtiveram no mínimo 3 pesquisadores que mais publicaram na Turismo em Análise de 2004 até 2015.

Gráfico 2 - Áreas de graduação que mais publicaram na revista Turismo em Análise (2004-2015)

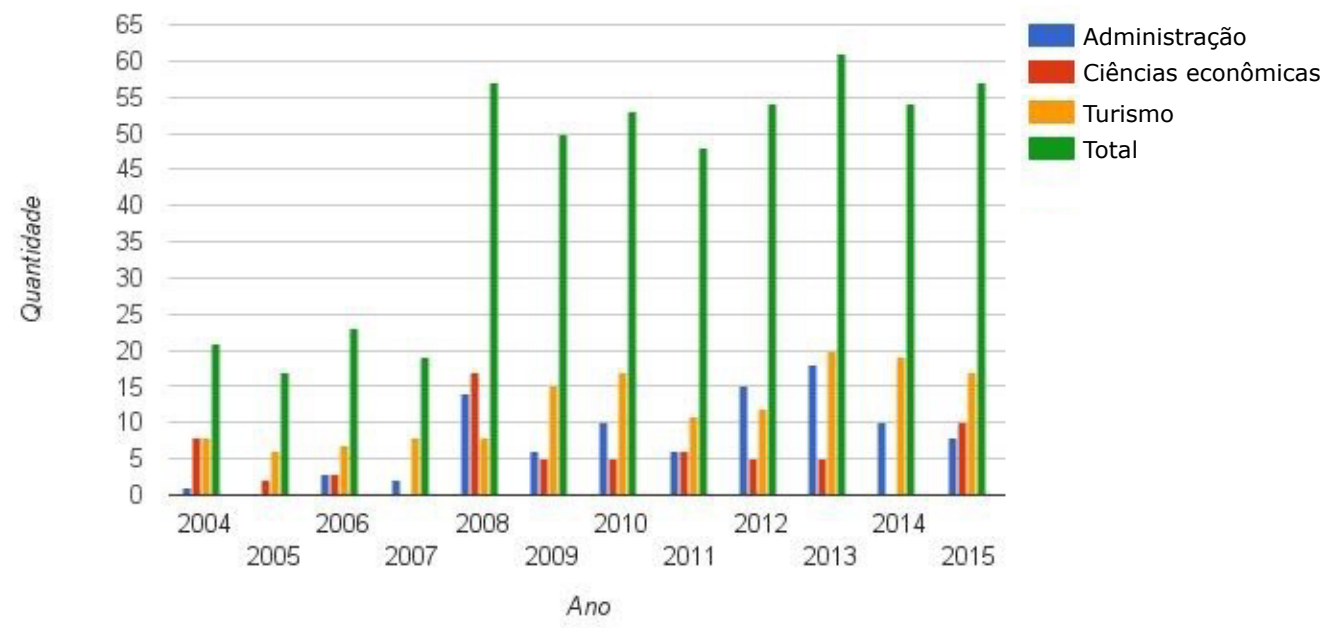

Fonte - Elaborado pelas autoras com dados da pesquisa

Gráfico 3 - Áreas de mestrado que mais publicaram na revista Turismo em Análise (2004-2015)

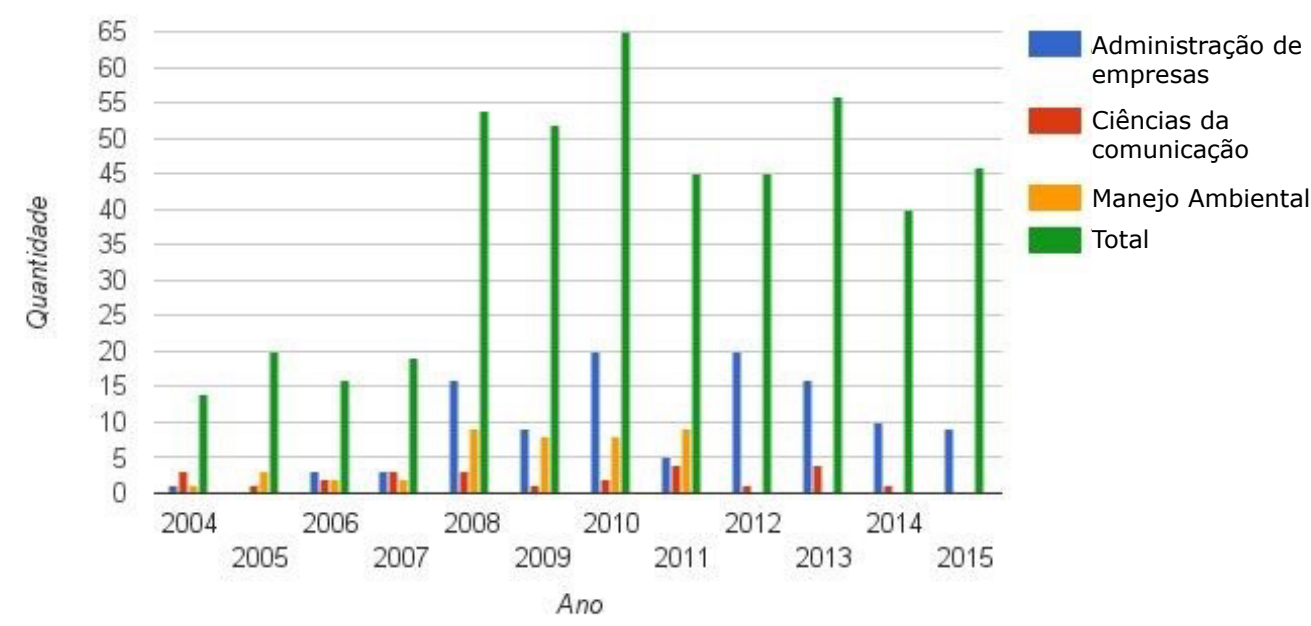

Fonte - Elaborado pelas autoras com dados da pesquisa 
Gráfico 4 - Áreas de doutorado que mais publicaram na revista Turismo em Análise (2004-2015)

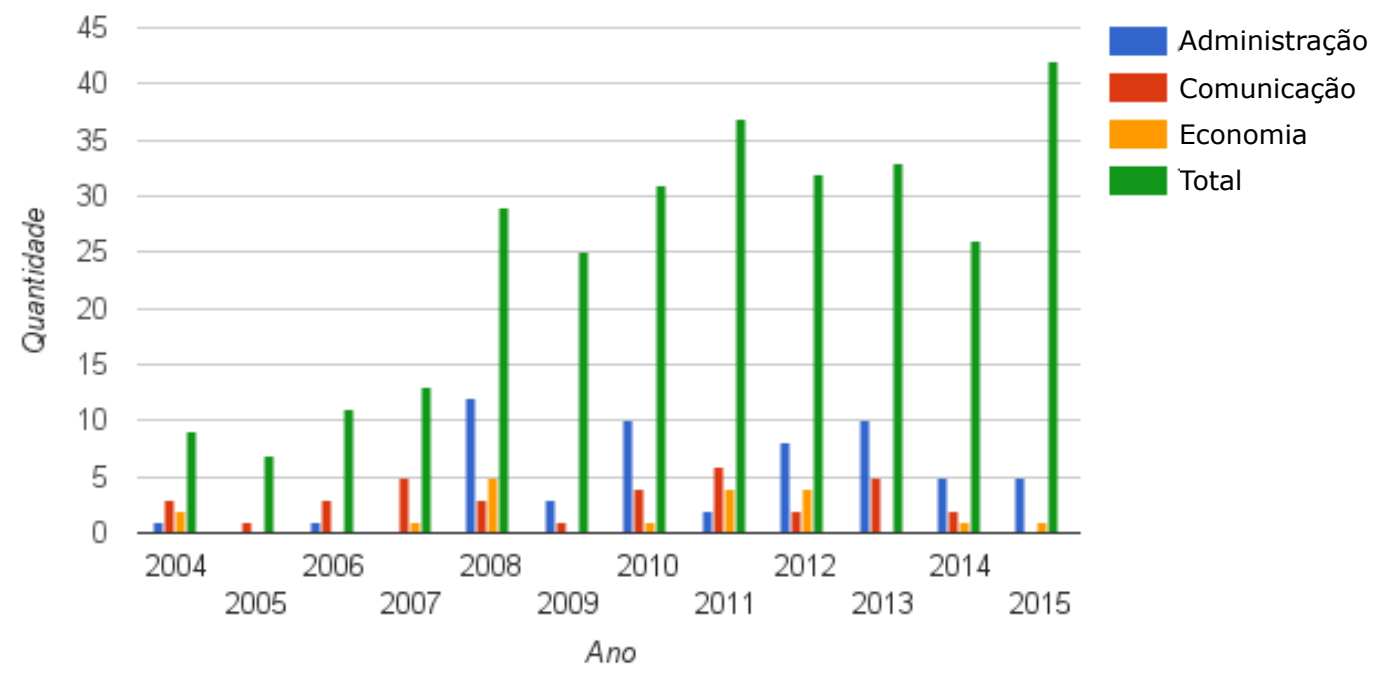

Fonte - Elaborado pelas autoras com dados da pesquisa

Nota-se uma tendência de pesquisas em turismo, geografia, economia, administração e comunicação. Estas foram as áreas com a maior quantidade de estudos e presença de interdisciplinaridade. Segundo Rejowski (2010), há necessidade de uma avaliação da produção científica no turismo, pois "quanto mais rápido e diversificado o desenvolvimento de uma área, maior a necessidade de pesquisas sobre a sua produção científica, ou de avaliação desta". Daí a importância da

realização de pesquisas de metaciência, que permitem analisar e avaliar a qualidade e efetividade do conhecimento produzido em uma determinada área, bem como suas necessidades e déficits. 0 próprio progresso científico se relaciona ou depende de avaliações sistemáticas da produção e do trabalho dos pesquisadores, o que garante o aperfeiçoamento constante não só do conhecimento, como também do próprio ensino. (Galemberck, 1990, apud Rejowski, 2010, p. 225)

Este fato tem sido nitidamente percebido na produção científica do turismo. Segundo Panosso e Calciolari, "numa possível comparação da área do turismo com outros campos e ciências, tais como a geografia, história, antropologia ou sociologia, ficaria latente a carência de publicações sobre esse assunto no Brasil" (Panosso \& Calciolari, 2010, p. 683). Ao que parece, ocorre uma corrida para determinar a metodologia da área, a fim de que assim proceda como as ciências mais consolidadas, nas quais, para se falar, escrever e pesquisar deve-se, intrínseca e minimamente, conhecer a área de estudos pesquisada. Já no turismo, atualmente entende-se que "qualquer um" pode falar, pesquisar ou escrever. Então, para que esta avaliação seja feita, deve-se levar em consideração que

de um lado, estudos que avaliem a produção científica decorrente das pesquisas turísticas, demonstrando as suas particularidades no contexto do campo recente de estudos que é o Turismo, podem oferecer importantes subsídios para a definição de critérios e indicadores de avaliação da produção científica na área. De outro, tratar da comunicação científica em Turismo, em especial da comunicação formal escrita 
(impressa ou eletrônica), envolve a compreensão do seu processo ou fluxo e suas particularidades, que podem então ser comparadas com áreas mais consolidadas. Nesse sentido, tais estudos podem refletir o "estado-da-arte" de uma área ou campo de estudos, como o estágio atual do conhecimento científico em Turismo no Brasil. (Rejowski, 2010, p. 225)

A qualidade das pesquisas é de suma importância para a produção científica, pois de nada adianta um elevado produtivismo científico, se este não for eficaz, gerando efeitos transformadores para a atividade turística. Se a ciência não se consolida, a atividade turística tampouco se consolida e é observada e valorizada como atividade econômica, como ferramenta educacional e de transformação social. Para tanto,

o desenvolvimento de qualquer área científica está diretamente relacionado, dentre outros fatores, com a quantidade e, principalmente, com a qualidade da pesquisa feita e publicada em tal área. Gradativamente, o conhecimento produzido passa por revisões e refutações, sendo testado e aprimorado, na tentativa de estabelecer a sua validade e utilidade. (Panosso Netto \& Calciolari, 2010, p. 669)

Um dado importante encontrado na pesquisa de Panosso Netto e Calciolari (2010) acerca da produção bibliográfica de livros de turismo publicados no Brasil aponta a seguinte análise:

A tendência [é] de que a queda de títulos publicados pode estar chegando ao seu limite. De acordo com a nova reestruturação e diretrizes de turismo, novos cursos estão sendo oferecidos, principalmente pelas instituições de ensino públicas, bem como os cursos de pós stricto senso estão se fortalecendo, fatores que podem levar a uma retomada de publicações na área, mesmo que seja tímida. Esse fato de poucas editoras no momento estarem interessadas em publicar livros de turismo reflete-se na criação de uma demanda reprimida de autores que possuem trabalhos prontos para publicação, mas não conseguem ter tais trabalhos aceitos. Nesse sentido, pode ocorrer uma procura por editoras que, mediante pagamento dos custos de edição, publicam a obra. Outra saída é o autor transformar seu livro em artigos e assim publicar em revistas científicas da área ou apresentar seus estudos em congressos científicos. (Panosso Netto \& Calciolari, 2010, p. 678)

A observação dos autores em relação à queda de publicações de livros de turismo foi identificada nesta pesquisa, o que ocorreu também na Turismo em Análise, onde as publicações aumentaram tanto quantitativa como qualitativamente. Ademais, aumentaram as publicações de pesquisadores com pós-graduação em turismo. Houve ainda um aumento significativo na quantidade de artigos publicados desde o início da revista, em 1990, sendo que até 2007 variaram entre 12, 13 e 15 artigos por ano, e a partir de 2009 foi estipulado o limite de 30 artigos por revista, portanto os números permaneceram constantes até 2015 . Esse aumento nas publicações em turismo nos últimos 25 anos demonstra um crescimento de 50\% das publicações. Em 2006 e 2015, houve uma revista extra (em cada ano) editada pela Turismo em Análise, chamada de "número especial", o que responde pelo crescimento de 2006 e 2015 e a queda de 2007. Um outro dado 
encontrado é que passaram a surgir pesquisas relacionadas às metodologias e às produções científicas de turismo a partir de 2010: as revistas dos anos 2010, 2011, 2012 e 2015 possuem pelo menos 3 artigos, em cada uma, que abordam a metodologia científica no turismo.

Há um crescimento e um desenvolvimento econômico de muitas cidades pelas receitas geradas por meio da atividade turística, que ocorre por investimentos dos poderes públicos e privados, dados que podem ser conferidos no site do Ministério do Turismo. Muitas cidades têm buscado tornar-se destino turístico, investindo nessa atividade e divulgando a cidade como destino apto a receber turistas. Essas cidades buscam analisar as potencialidades turísticas para segmentar o destino, mesmo que para eventos sazonais:

entretanto, não obstante a importância da qualidade, satisfação, fidelidade e imagem de destinos turísticos como fatores direcionadores de competitividade, estes não têm tido uma devida atenção na literatura. Embora, em outras áreas de estudo, o constructo satisfação, assim como os demais, já tenha sido amplamente trabalhada, nos estudos em turismo este item ainda possui um escasso material de referência, principalmente no que diz respeito ao desenvolvimento de modelos, métodos e instrumentos específicos da área, como afirmam Bedia, Fernández e López, (2007), Yilmaz (2009), Juwaheer (2004) Akbaba (2006) Albacete-Sáez, Fuentes-Fuentes e Lloréns-Montes (2007). (Chagas \& Marques, 2010, p. 496)

Esta afirmação reforça a discussão, já em um panorama internacional de avaliação da produção científica no turismo, como parte do desenvolvimento econômico das cidades, e reafirma a defesa de que a produção científica está interligada aos investimentos da atividade turística, precisando ser consolidada para que os investimentos e pesquisas de planejamento sejam cada vez mais eficientes.

Foram encontrados 99 temas e abordagens de estudos diferentes, totalizando 1312 abordagens do tema ao longo dos artigos dos últimos 12 anos: planejamento e desenvolvimento turístico, 122 vezes; estratégia de planejamento/ gestão/política, 72 vezes, e impacto econômico, 59 vezes.

\section{Áreas de estudo dos autores}

O levantamento das áreas de formação dos pesquisadores deu-se pelo conhecimento tanto das áreas interessadas em estudar o turismo quanto pela aferição da quantidade de pesquisadores da área do turismo (bacharéis, mestres e doutores) e a análise do modo como estão estudando o turismo em uma perspectiva de conceitos e entendimento de sua complexidade social, econômica, cultural e ambiental.

Em alguns artigos, houve dificuldade de encontrar a metodologia utilizada, pois além de não haver uma seção específica para metodologias, estas eram explicadas breve e esparsamente em diversas seções, como na introdução, nas discussões e na análise dos resultados, ou apenas citadas no resumo. Estes casos foram notados em $100 \%$ dos artigos cujos autores não possuem alguma formação em turismo. Ao ler um artigo fica patente o cuidado que autores das áreas do turismo têm em apresentar as metodologias e expor e discorrer acerca das complexidades que envolvem a atividade turística. Então, ao longo das leituras, antes 
mesmo de saber as áreas de formação dos autores, era possível saber se estes eram ou não do turismo, tendo-se em mente que a área passou muitas décadas discutindo, nacional e internacionalmente, seus conceitos, termos e definições. Há maturidade acadêmica e obras clássicas para quem estuda a área, com ampla e aprofundada discussão de seus conceitos genéricos e específicos de acordo com os segmentos turísticos, suprindo as expectativas de pesquisadores do turismo e dando credibilidade ao campo. Essas obras sevem ser referências, pois o turismo é uma área inter e multidisciplinar, necessitando, portanto, de pesquisas detalhadas das áreas interligadas a ele.

\section{Mapeamento metodológico}

Sobre a utilização dos resultados verificou-se que as pesquisas de caráter puro/básico obtiveram 47,1\%, e as de caráter fundamental e aplicado, 52,9\%. Considera-se que há um equilíbrio, assim como com os resultados obtidos sobre a natureza dos dados, dos quais $60,8 \%$ foram de pesquisas objetivas e 39,2\%, subjetivas. Ainda que as objetivas estejam presentes em maior quantidade que as subjetivas, não considera-se uma diferença que deva gerar discussões, pois em alguns artigos houve dificuldades para definir em qual natureza dos dados as pesquisas se encaixavam - algumas foram consideradas tanto objetivas quanto subjetivas. 0 mesmo ocorreu em relação à procedência dos dados, nos quais 52,6\% são pesquisas primárias (estudo de caso) e 47,4\% secundárias (revisões, análises econômicas).

Já em relação ao grau de generalização dos resultados, observa-se uma tendência das amostragens, sendo intencional e aleatória as mais utilizadas, com uma diferença de quase 20 pontos entre estas. Ambas definem características diferentes de pesquisa, no entanto, são muito utilizadas. 0 número é bastante significativo, pois mais de um terço do conjunto de dados foi de amostragem aleatória e intencional, indicando uma tendência à pesquisa quantitativa. Observa-se, porém, que embora as pesquisas de caráter quantitativo sejam mais numerosas, há um crescimento de pesquisas participativas, frutos de entrevistas e anamnese que buscam estreitar o contato e a vivência e compreender melhor a realidade local dos entrevistados a fim de que haja um entendimento e uma análise mais aprofundada das relações sociais, ambientais e culturais, ultrapassando análises de dados econômicos feitas apenas pela perspectiva do crescimento.

Foram encontradas mais de 200 metodologias de pesquisa diferentes, algumas desenvolvidas especificamente para alguma determinada pesquisa, outras já existentes e experimentadas pelo turismo, além de metodologias de outras áreas já consolidadas e outras desconhecidas no Brasil porém utilizadas por pesquisadores estrangeiros de turismo. As metodologias mais utilizadas foram as de pesquisas puras/básicas com utilização dos resultados; com natureza dos dados objetivos; de procedência dos dados primários (estudo de caso); do grau de generalização dos resultados, amostragens intencionais; e as técnicas e os instrumentos de observação mais utilizados nas pesquisas foram: observação direta, observação participante, consultas bibliográficas e consultas de dados.

Os dados da Tabela 1 demonstram que não há uma metodologia ou um conjunto de metodologias já consolidadas sendo predominantemente utilizadas nas 
pesquisas. 0 que existe é uma grande inter e multidisciplinaridade, uma elevada produção científica de artigos e um aumento significativo no período contemplado. No entanto, nota-se uma tendência a determinadas pesquisas, tais como documentais, participativas, bibliográficas, descritivas, exploratórias e de observação. Nota-se, ainda, um aumento de pesquisas de comportamento, método survey, para casos de mercado e investimentos, tanto para crescimento econômico quanto desenvolvimento local. A análise fatorial e o estudo de caso múltiplo também fazem parte da tendência metodológica nos últimos 12 anos.

Discute-se profusamente acerca da inter e multidisciplinaridade do turismo e nota-se a abrangência de áreas de formação dos pesquisadores que publicaram na revista. No entanto, houve dificuldade de determinar as disciplinas em pesquisas extremamente específicas, como as de planejamento turístico, turistificação de locais e políticas de turismo. Também nessas pesquisas há discussões sobre aspectos econômicos, sociais, ambientais, culturais, políticos ou urbanísticos. Tudo parece levar aos conceitos que se formam nessas áreas, ou seja, ao se estudar o turismo, compreende-se como únicas estas áreas do conhecimento, assim como ao se estudar sociologia estuda-se também conceitos de economia, muitas vezes de meio ambiente, de história etc. Surgiram também dificuldades em definir as disciplinas envolvidas, pois alguns artigos aparentemente pareciam abordar conceitos de administração, contudo confundiam-se com a economia. Esses estudos foram definidos como interdisciplinares. Com efeito, defende-se o turismo como uma disciplina, pois para abordá-lo fazem-se necessários conceitos de diversas outras áreas, que entrelaçam-se nos conceitos, tornando-se peculiares à área do turismo. Assim, conceitos adequam-se ao turismo, tornando-se específicos da área, gerando a dificuldade de definir as disciplinas envolvidas nas pesquisas, principalmente as pesquisas bem específicas, como as que se debruçam sobre o desenvolvimento turístico, as políticas de turismo e o profissional do turismo. A Tabela 1 contém as metodologias encontradas e o número de vezes que foram utilizadas. Esta tabela trata das metodologias e técnicas de pesquisa que os autores dos artigos consideraram como método.

Tabela 1 - Metodologias e técnicas de análise encontradas na revista

Turismo em Análise entre 2004-2015

\begin{tabular}{|l|c|}
\hline Metodologias e técnicas de análise encontradas & Total \\
\hline Análise fatorial (multivariada, confirmatória) & 13 \\
\hline Análise categorial (técnica de análise de conteúdo) & 1 \\
\hline Análise conjunta de preferência declarada & 1 \\
\hline Análise de documentos históricos & 1 \\
\hline Análise do discurso & 2 \\
\hline Análise cognitiva & 1 \\
\hline Análise dos componentes principais (ACP) & 1 \\
\hline Análise de conteúdo (free elicitation) - modelo de Baloglu (1999) & 3 \\
\hline Análises do efeito mediador & 1 \\
\hline Análise de percepção & 2 \\
\hline Análise de portfólio dos produtos - elaborada pelo Boston Consulting Group & 1 \\
\hline
\end{tabular}


Tabela 1 - Continuação

\begin{tabular}{|c|c|}
\hline Metodologias e técnicas de análise encontradas & Total \\
\hline Análise de regressão múltipla & 4 \\
\hline Análise de variância multivariada (Manova) & 2 \\
\hline Auditoria dos stakeholders - influências e identificação (Freeman, 1984) & 1 \\
\hline Avaliação ambiental estratégica (AAE) - planejamento & 1 \\
\hline Avaliação empírico-analítica & 5 \\
\hline Bibliometria - mapear a estrutura do conhecimento & 2 \\
\hline Bruschi (impacto ambiental) & 1 \\
\hline Cálculo amostral: fórmula de população infinita & 1 \\
\hline Capacidade coletiva: organizacional, instrumental esistémica & 1 \\
\hline Cariz qualitativo/intensivo & 1 \\
\hline Cifuentes (capacidade de carga) & 1 \\
\hline $\begin{array}{l}\text { Cifuentes-Arias, Swarbrooke e Boggiani (capacidade de suporte e conservação } \\
\text { da natureza) }\end{array}$ & 1 \\
\hline Coeficiente de demanda turística & 1 \\
\hline Confiabilidade, validade de constructo, construção de escalas e equações estruturais & 1 \\
\hline Confiabilidade & 3 \\
\hline Confiabilidade - cálculo do Alpha de Cronbach & 3 \\
\hline Corte transversal & 2 \\
\hline Comp\&tenible model: avaliação da sustentabilidade estratégica de destinos turísticos & 1 \\
\hline Cointegração (equilíbrio L.P.) & 1 \\
\hline Cross-sectional & 1 \\
\hline Diagnóstico rural participativo - DRP (Verdejo, 2006) & 1 \\
\hline Diário de campo & 3 \\
\hline Discurso do sujeito coletivo (Lefèvre \& Teixeira, 2000) & 1 \\
\hline Distribuição e frequência e tabulação cruzada & 2 \\
\hline Dwyer (2005) - modelo de recuperação de áreas pós-desastre natural & 1 \\
\hline Dywer e Kim (modelos de avaliação de competitividade de destinos turísticos) & 1 \\
\hline Delphi & 2 \\
\hline Discussão em grupo (Flick, 2004) & 1 \\
\hline Empírica & 1 \\
\hline Entrevista semi-dirigidas & 1 \\
\hline Escala SERVQUAL (qualidade percebida) & 2 \\
\hline Escala de análise de humor de Norris (1971) - coleta de dados sobre percepção & 1 \\
\hline Escala multidimensional (intenções de comportamento) & 1 \\
\hline Escala Markor & 1 \\
\hline Escala de satisfação de Lickert & 8 \\
\hline Econometria (estimativa da demanda) & 2 \\
\hline Estatística & 8 \\
\hline Escala para mensuração do construto intensidade moral & 1 \\
\hline Estimativa dos coeficientes & 1 \\
\hline Estudo de caso múltiplo & 11 \\
\hline Fenomenologia & 3 \\
\hline Ferramentas de geoprocessamento & 1 \\
\hline Fluxograma & 1 \\
\hline Fórmula de Triola (calcular o tamanho das amostras) & 1 \\
\hline
\end{tabular}


Tabela 1 - Continuação

\begin{tabular}{|c|c|}
\hline Metodologias e técnicas de análise encontradas & Total \\
\hline $\begin{array}{l}\text { Fórmula do quociente locacional da teoria da base econômica regional - mede a } \\
\text { concentração de uma certa atividade numa determinada área }\end{array}$ & 1 \\
\hline Formulário de Manzato & 1 \\
\hline Google Docs - ferramenta de internet & 1 \\
\hline Gestão estratégica orientada para resultados (Geor) & 1 \\
\hline História oral & 5 \\
\hline Histórico-genética & 1 \\
\hline Holística e pluralista & 1 \\
\hline LOGIT (modelo logístico - probabilidade de satisfação) & 1 \\
\hline Indicadores de turismo sustentável & 1 \\
\hline Inquérito & 1 \\
\hline Investigação & 1 \\
\hline $\begin{array}{l}\text { Investigação (analítico-sintético, histórico-lógico, indutivo-dedutivo e sistêmico- } \\
\text { estrutural) }\end{array}$ & 1 \\
\hline $\begin{array}{l}\text { Investigação (atributos para caracterização: geológicos; geomorfológicos; } \\
\text { fitogeográficos e hidrográficos) }\end{array}$ & 1 \\
\hline Insumo-produto (equliíbrio geral) & 1 \\
\hline Intervenção participativa dos atores - INPA (Furtado \& Furtado, 2000) & 1 \\
\hline LAC (impacto de visitação) & 1 \\
\hline Levantamento de comportamento (Survey) & 10 \\
\hline Survey monkey & 2 \\
\hline Laville e Dionne (emparelhamento com a discussão conceitual) & 1 \\
\hline Matriz de avaliação (potencialidades turísticas, comparativo) & 1 \\
\hline Magro (trilha, solo, declividade, vegetação, estética, lixo) & 1 \\
\hline Mapa astral & 1 \\
\hline Matrizes de atributos (análise de resultado) & 1 \\
\hline $\begin{array}{l}\text { Mensuração da imagem cognitiva e imagem afetiva do destino (variáveis) - Beerli e } \\
\text { Martín (2004) }\end{array}$ & 1 \\
\hline Método experimental & 1 \\
\hline Método de modelagem de equações estruturais (MEE) & 1 \\
\hline Método de estimação de parâmetros da máxima verossimilhança (MLE) & 1 \\
\hline $\begin{array}{l}\text { Método hierárquico aglomerativo da ligação completa - grupos com características } \\
\text { similares) }\end{array}$ & 1 \\
\hline $\begin{array}{l}\text { Método Q - análise da relação entre as opiniões das categorias de indivíduos da } \\
\text { população amostrada }\end{array}$ & 1 \\
\hline Metodologia mista - visão dos turistas da imagem de um destino turístico & 2 \\
\hline Mínimos quadrados (ordinário MQO - C.P.) & 1 \\
\hline Modelagem de equação estrutural & 1 \\
\hline Modelo de Abermathy e Clark & 1 \\
\hline Modelo de questionário da demanda Embratur & 1 \\
\hline Modelo Porter (1991) (tipologia de posicionamento estratégico) & 1 \\
\hline Modelo de Miles et al. (1978) (comportamento estratégico) & 1 \\
\hline
\end{tabular}


Tabela 1 - Continuação

\begin{tabular}{|c|c|}
\hline Metodologias e técnicas de análise encontradas & Total \\
\hline Modelo de restrição ao lazer - Crawford, Jackson, \& Godbey (1991) & 1 \\
\hline $\begin{array}{l}\text { Modelo de Wilson e Vlosky (1997) e Larentis e Slongo (2008) - mensuração de } \\
\text { marketing de relacionamento }\end{array}$ & 1 \\
\hline Modelo de análise Chi e Qu (2008) - destinos de sol e praia & 1 \\
\hline Medida de adequação da amostra (KMO) & 1 \\
\hline Mapa conceitual & 1 \\
\hline Método de valoração contingente (MVC) - análise de valoração econômica ambiental & 1 \\
\hline Método biográfico & 1 \\
\hline Método de componentes principais e rotação varimax & 1 \\
\hline Método de Pearson - verifiica a força da significância e o tipo de relação & 1 \\
\hline Observação & 25 \\
\hline OMT (2005) - configuração regional & 1 \\
\hline Poligonal aberta, fechada e irradiação & 1 \\
\hline Pesquisa de ação participativa & 5 \\
\hline Procedimento operacional padrão (POP) & 1 \\
\hline Programa Raosoft & 1 \\
\hline Programa Atlas.ti (análise de dados) & 1 \\
\hline Planejamento estratégico participativo - PEP (Diesel et al., 2004) & 1 \\
\hline Pesquisa iconográfica & 1 \\
\hline Questionário de saúde geral de Goldberg - 60 itens (instrumento de rastreamento) & 1 \\
\hline $\begin{array}{l}\text { Questionário: Hoffmann (2002), modificado e utilizado por Costa (2005), junto aos } \\
\text { componentes do universo de pesquisa: os atores sociais representativos do setor } \\
\text { público, setor privado e entidades }\end{array}$ & 1 \\
\hline Questionário de vivências acadêmicas (QVA-r) & 1 \\
\hline Regressivo-progressivo & 1 \\
\hline Regressão logística - método stepwise (Agresti, 2007) & 1 \\
\hline SERVPERF & 1 \\
\hline Snowball & 1 \\
\hline $\begin{array}{l}\text { Software Statistical Package for Social Sciences } \\
\text { (SPSS) }\end{array}$ & 1 \\
\hline SWLS - Satisfaction with Life Scale & 1 \\
\hline Swot & 1 \\
\hline Triangulação de dados & 3 \\
\hline Teorema de Bayes, ou árvore de probabilidade & 1 \\
\hline Técnica de emparelhamento (comparação) & 1 \\
\hline Técnica da exaustão & 1 \\
\hline Técnicas historiográficas de pesquisa e análise & 1 \\
\hline Teste de esfericidade de Bartlett & 1 \\
\hline Total & 232 \\
\hline
\end{tabular}

Fonte - Elaborado pelas autoras com dados da pesquisa. 


\section{CONSIDERAÇÕES FINAIS}

Conclui-se que novas possibilidades de pesquisas na área têm surgido e aprimorado a qualidade dos artigos publicados na revista Turismo em Análise. No entanto, é preocupante a quantidade de metodologias encontradas (232): dado que resulta da quantidade de pesquisadores de outras áreas, pelo fato de o turismo ser uma área inter e multidisciplinar. Inegável é a necessidade, após anos de estruturação científica do turismo, de metodologias serem estabelecidas pela e para a área.

Esta pesquisa teve como objeto a Turismo em Análise, uma revista que existe há 27 anos com publicações ininterruptas, e que recebe artigos de vários lugares do mundo. Fica ainda a necessidade de se realizar pesquisas em outras revistas, de todos os continentes, mas em um primeiro momento do Brasil e da América do Sul, onde estariam mais presentes e retratadas as realidades locais, para que o delineamento de propostas metodológicas seja mais condizente com as realidades regionais. Entretanto, o que podemos concluir é que de fato existem mais de duzentas metodologias sendo utilizadas, e que diversas áreas de estudo envolvidas nas publicações e pesquisadores das áreas do turismo estão aumentando. Ainda que afirme-se que o turismo é uma área inter e multidisciplinar, conclui-se que é de suma importância a realização de pesquisas sobre seu próprio processo de desenvolvimento (metodologias e teorias), para que as demais pesquisas da área sejam melhor desenvolvidas e mais rapidamente consolidadas.

Esta pesquisa não é conclusiva, visto que muito ainda deve ser pesquisado para expandir o conhecimento do turismo e as discussões acerca dos segmentos, implicações e benefícios que esta atividade promove para as sociedades e as dinâmicas espaciais.

\section{REFERÊNCIAS}

ARANHA, M. L., \& Martins, M. H. P. (1986). Filosofando: introdução à filosofia. São Paulo: Moderna.

BARRETO, M. (1995). Manual de iniciação ao estudo do turismo. Campinas: Papirus.

CHAGAS, M. M., \& Marques, S. (2010). Análise da relação causal entre imagem, qualidade, satisfação e fidelidade: um estudo sobre a percepção do turista nacional no destino turístico Natal/RN. Turismo em Análise, 21(3), 494-516.

DENCKER, A. F. M. (1998). Métodos e técnicas de pesquisa em turismo. São Paulo: Futura. ECO, U. (1976). Como se faz uma tese. São Paulo: Perspectiva.

KOCHE, J. C. (2009). Fundamentos de metodologia científica. Petrópolis: Vozes.

NECHAR, M. C. (2011). Epistemología critica del turismo ¿qué es eso?. Turismo em Análise, São Paulo. Vol. 22, n. 3.

PANOSSO Netto, A., \& Calciolari, G. F. M. (2010). Quantos são os livros teóricos de turismo publicados no brasil? Uma análise da produção bibliográfica nacional (1990-2010). Turismo em Análise, 21(3), 668-686.

REJOWSKI, M. (1996). Turismo e Pesquisa Científica: pensamento internacional X situação brasileira. Campinas: Papirus.

REJOWSKI, M. (2010). Produção científica em turismo: análise de estudos referenciais no exterior e no Brasil. Turismo em Análise, 21(2), 224-246. 
REJOWSKI, M., \& Kobashi, N. Y. (2011). Subsídios para elaboração de um tesauro brasileiro de turismo. Turismo em Análise, 22(3), p. 579-598.

REJOWSKI, M., \& Minozzo, C. C. (2004). Periódicos científicos em turismo: panorama evolutivo e caracterização da revista Turismo em Análise. In Anais Intercon. Porto Alegre. Disponível em: https://goo.gl/2G3N6Y

REJOWSKI, M.; Miranda, E. C. P. (2012). Panorama dos periódicos científicos de turismo e hospitalidade no Brasil. In IX Seminário da Associação Nacional de Pesquisa e Pós-Graduação em Turismo. São Paulo: Universidade Anhembi Morumbi.

SEVERINO, A. J. (2002). Metodologia do trabalho científico. São Paulo: Cortez.

Recebido em: 26/03/2017

Aprovado em: 11/09/2017

\section{CONTRIBUIÇÕES}

Camila Lopes Seixas: definição do problema de pesquisa e objetivos, desenvolvimento da proposição teórica, realização da revisão bibliográfica e fundamentação teórica, escolha dos procedimentos metodológicos, coleta de dados, análise de dados, elaboração de tabelas, gráficos e figuras, realização de cálculos e projeções, redação do manuscrito, adequação do manuscrito às normas da RTA.

Monica Filomena Caron: definição do problema de pesquisa e objetivos, desenvolvimento da proposição teórica, escolha dos procedimentos metodológicos, revisão crítica do manuscrito, redação do manuscrito. 